\title{
Finite element analysis of actively controlled heavy rotor using PVDF piezoelectric layer as sensor and actuator
}

\author{
Tarun Kumar ${ }^{1,1}$, Rajeev Kumar², and Satish Jain ${ }^{2}$ \\ ${ }^{1}$ Indian Institute of Technology Mandi \\ ${ }^{2}$ Affiliation not available
}

May 5, 2020

\begin{abstract}
Reduction in the torsional vibration of heavy rotors like turbo-generator rotor is important for the safe and efficient functioning of the power plant. In this paper theoretical study is performed to control the torsional vibration in the turbo-generator rotor using piezoelectric material as sensor and actuator. Polyvinylidene fluoride (PVDF) layer is used as sensor and actuator. Proportional and velocity feedback is used as control law. The variation in the electromagnetic torque of synchronous generator during various electrical faults is evaluated using dq0 model. Finite element method is used to model the rotor elements. The coupled equations are solved in MATLAB using Newmark-beta integration method. The coupling elements of turbine and generator are most susceptible to the shear failure so torsional vibration of coupled rotor on coupling elements are compare for controlled and uncontrolled scenario. Simulation results show that for actively controlled rotor significant reduction in the amplitude of torsional vibrations is observed.
\end{abstract}

\section{Hosted file}

Main Document_ER.pdf available at https://authorea.com/users/237333/articles/424711-finiteelement-analysis-of-actively-controlled-heavy-rotor-using-pvdf-piezoelectric-layer-assensor-and-actuator 